\title{
Issues in Italo-Romance morphosyntax
}

\author{
Diego Pescarini \\ University of Zurich \\ diego.pescarini@uzh.ch \\ Silvia Rossi \\ University of Bologna \\ silvia.rossi39@unibo.it
}

The present monographic issue collects several selected papers presented at the 2014 Cambridge Italian Syntax-Morphology Meeting, with the intent of offering a clear, bird-eye overview on recent advances in a series of empirical and theoretical issues in Italo-Romance morpho-syntax.

The contributions here collected are up-to-date in-depth studies by both prominent experts and promising young scholars who address some classical topics in (Italo)Romance linguistics such as particle syntax, subject clitics, verbal morphology, negation, and nominal inflections, presenting new empirical findings on both well-known distributional patterns and previously unnoticed correlations. In line with most of the formal studies in Italo-Romance linguistics of the past two decades, the strong idea underlying all the contributions is that the high degree of microvariation exhibited by Italo-Romance varieties in all areas of grammar offers a large empirical domain for investigating and identifying new generalizations on and correlations among major linguistic phenomena. Since Kayne (2005), microcomparative environments are taken as an ideal test-bed for predictions and hypotheses since certain syntactic properties and distributions, which can be seen at work on a greater scale in many different languages, can be more easily controlled for in closely related languages where they vary minimally while the core of the grammatical system remains uniform.

Thus, taking a wealth of microcomparative evidence as their starting point, one of major aims of all the contributions in this issue is to refine, critically discuss or even challenge some of the major theoretical tenets and results of generative frameworks such as Distributed Morphology, Minimalism and Cartography, with innovative analyses, which can be extended to similar phenomena within the Romance domain and beyond. Moreover, besides purely syntactic analyses, this volume offers also a number of insights on other subbranches of formal linguistics and explores grammatical puzzles at the interface between syntax and semantics or pragmatics.

The first contribution, Guido Mensching's paper, explores exactly the 
interface between syntax and pragmatics, taking into account the Sardinian question particle $a$ (probably < lat. AUT) of yes/no 'special' questions. Following Obenauer $(2004,2006)$, this particle is taken to mark special interrogative clauses that cannot be answered with yes or no as they denote invitations or requests, express surprise, or are biased towards an answer (as in so-called rhetorical questions).

Franco, Manzini and Savoia address a much studied topic in ItaloRomance morphosyntax, i.e the so called 'neuter' $-O$ nominal inflection of Central-Southern Italian varieties, which for some varieties is marked only on D elements and is syncretic with masculine on nouns and adjectives, while in some other varieties $-O$ is found both on Ds and on lexical categories, including participles.

Unlike traditional accounts of Central-Southern Italian neuter which maintain that $-o$ is a gender morpheme with no interpretative content, the authors' proposal is to treat $-O$ as an instance of $\mathrm{N}$ class morphology encoding mass/count distinction (an approach supported also by typological evidence). This is in turn a reflex of a more primitive property opposing non-individual vs. individual denotation as the $-o$ inflection is found also in other domains outside the strictly nominal one (for instance, in past participle agreement with unergative/transitive verbs or with propositional/eventive content). From a more theoretical perspective, the analysis proposed departs also from the standard Minimalist view of Agree as it is argued that there are no uninterpretable features and agreement morphology is always interpretable.

The paper starts with a thorough and detailed description of the syntax of yes/no $a$-questions in Sardinian, showing that this interrogative particle is incompatible with negation and focus fronting, forces the subject to occur in postverbal position, and frequently co-occurs with clitic right dislocations. After a critical revision of the formal literature on on $a$, the author's proposal departs from previous accounts under two main respects: first, he argues that the question particle $a$ is a head merged in Foc $^{\circ}$ and moved to one of Obenauer's SpIntP (special interrogative phrase). Second, he points out that in $a$-questions nominal constituents are obligatorily dislocated. He proposes that DPs are extracted to a functional projection beneath FocP before the remnant TP is moved to [spec, FocP].

Andrea Calabrese deals with irregularities in the morphological make-up of Italian verbal forms, focusing on perfect and past participle forms. He aims to account for root-based contextual allomorphy, i.e. idiosyncratic patterns of irregularity affecting certain roots, in the framework of Distributed Morphology (Halle \& Marantz 1993). In particular, he shows that morphological irregularities can be handled with basic morphological devices such as vocabulary items (VI) and morphophonological (MP) rules having root-information in their structural description.

Building upon the generalisation that allomorphy occurs with athematic forms, he hypothesizes that morpheme-to-morpheme interactions can occur only in a local configuration, i.e. under linear adjacency (Embick 2010). Morphological irregularities results whenever the thematic vowel is absent. Thus, provided that the distribution of thematic and athematic forms is unpredictable, he claims that irregularities follow from a series of morpho-phonological rules 
triggered by the absence of the thematic vowel.

On the basis of these assumptions, Calabrese accounts for the synchronic morphology of past perfect and past participle forms and provides a diachronic analysis of the evolution of perfect forms by means of a restricted set of morphophonological rules.

The article challenges the traditional view according to which morphological irregularities follow from stress positioning. Rather, he argues that verbal stress is predictable and, in particular, that irregular perfect and past participle stems are stressed because the thematic vowel preceding the tense morpheme is missing. On a more general level, , Calabrese claims that historical irregularities and their emergence can be accounted for in a morpheme-based framework in which morphological computation proceeds from a morphosyntactic input - namely, a tree encoding functional features - which is manipulated by means of simple and internally motivated rules.

Masutti and Casalicchio focus on the subject clitics of the Friulian dialect spoken in Campone. They investigate the syntax of the clitic $a$, which is used to express both referential ( $3 p$ ) and non-referential (expletive) subjects. In the former case, $a$ combines with other clitic formatives giving rise to pronominal forms such as $a+l$ 'he' $a+i$ 'they.M' $a+s$ 'they.F'. Previous analyses (e.g. Poletto 2000) have suggested that clitics such as $a$ occupy a high position in the $\mathrm{CP}$ as they never occur in enclisis in case of $\mathrm{V}$-to-C movement. However, Masutti and Casalicchio notice that in Camponese $a$ does invert. Given this property, they conclude that $a$ cannot be located in the CP layer and draw a very detailed map of the functional area at the IP/CP border in order to capture the interaction of the clitic $a$ with other elements (DP subjects, negation, focused constituents, etc.). They conclude that the most suitable position for the clitic $a$ of Campone is the head of Rizzi \& Shlonsky's (2007) SubjP, thus excluding that $a$ incorporates on the verb in $\mathrm{T}^{\circ}$ as they are divided by NegP hosting no. Although the analysis does not account for the distribution of $a$ in negative interrogative (where no occurs in proclisis, while $a$ inverts), the paper offers an original contribution to the fine-grained analysis of the TC/CP border and, on the basis of a rich dataset, challenges previous accounts of nearby Friulian clitic systems.

Finally, Garzonio and Poletto explore another interesting phenomenon involving some feature hosted in the Left Periphery. Specifically, the authors investigate two types of preverbal negative markers found in some varieties of Sicilian, namely the "wrong expectation" negative adverb neca (Cruschina 2010, 2015), and the morphologically complex clitic negation $n$-un which alternates in specific syntactic contexts with the simple form $u n$. Both these negative items are argued to be merged in the $\mathrm{CP}$ layer and are considered cases of "syntactic parasitism": neca, diachronically derived from a structure containing the negated copula and a postverbal Focus position, "it is not that X", is a case of "featural parasitism' in that the historical presence of a focus feature in its structure allows this item to maintain its position in the CP domain even when its original focus semantics are lost. Similarly, the morpheme $n$ - of nun is considered a case of 'structural parasitism' in the sense that its merge position in a head of the Left Periphery is dependent on the presence in this layer of another item in a close structural position (much like the parasitic presence of the dative/oblique clitic in 
the resumptive clitic clusters of Italian left dislocation constructions involving two topicalised constituents, see Benincà 1988: 177-178),

On a more general level, Garzonio \& Poletto's paper show how a close inspection of the Italian dialectal microvariation can question some important theoretical tenets: neca and $n$-un pose a non-trivial challenge to the standard analysis of negation as a single [neg] feature and/or a single NegP, as these Sicilian negative markers clearly indicate that negation is semantically and syntactically complex, involving at least also a left peripheral feature (for instance, focus).

\section{References}

Benincà, Paola. 1988. 'L'ordine degli elementi nella frase'. In Grande grammatica italiana di consultazione. Vol. 1, ed. by Lorenzo Renzi et al., 115-194. Bologna: Il Mulino.

Cruschina, Silvio. 2010. 'Aspetti morfologici e sintattici degli avverbi in siciliano'. Quaderni di lavoro dell'ASIt 11: 19-39.

Cruschina, Silvio. 2015. 'The Expression of Evidentiality and Epistemicity: Cases of Grammaticalization in Italian and Sicilian." Probus 27: 1-31. http://dx.doi.org/10.1515/probus-2013-0006

Embick, David. 2010. Localism versus Globalism in Morphology and Phonology. Cambridge, MA: MIT Press. http://dx.doi.org/10.7551/mitpress/9780262014229.001.0001

Halle, Morris \& Marantz, Alec. 1993. Distributed Morphology and the pieces of inflection. In The view from Building 20: Essays in linguistics in honor of Sylvain Bromberger, Kenneth Hale \& Samuel Jay Keyser (eds), 111-176. Cambridge, MA: MIT Press.

Kayne, Richard S. 2005. "Some notes on Comparative Syntax, with special reference to English and French". In: The Oxford Handbook of Comparative Syntax, ed. by Guglielmo Cinque and Richard S. Kayne, 349. Oxford-New York: OUP. http://dx.doi.org/10.1093/acprof:oso/9780195179163.003.0012

Obenauer, Hans-Georg 2004. "Nonstandard wh-questions and alternative checkers in Pagotto". In: Horst Lohnstein and Susanne Trissler (eds): Syntax and Semantics of the Left Periphery, Interface Explorations 9. Berlin, New York: Mouton de Gruyter, 343-384. http://dx.doi.org/10.1515/9783110912111.343

Obenauer, Hans-Georg 2006. "Special Interrogatives - Left Periphery, WhDoubling, and (Apparently) Optional Elements". In: Jenny Doetjes and Paz Gonzalves (eds): Romance Languages and Linguistic Theory 2004 Selected Papers from 'Going Romance 2004', Amsterdam/Philadelphia: John Benjamins. 247-273. http://dx.doi.org/10.1075/cilt.278.12obe

Poletto, Cecilia 2000. The Higher Functional Field. Oxford: Oxford University Press.

Rizzi, Luigi and Ur Shlonsky 2007. "Strategies for subject extraction". In U. Sauerland \& H.-M. Gärtner (eds.), Interfaces + recursion = language? 
Chomsky's minimalism and the view from syntax-semantics. Berlin: Mouton de Gruyter, 115-160. 